Paula, S.F.; Castro, P.T.A Bases metodológicas e teóricas para

\title{
Bases metodológicas e teóricas para inventariação, qualificação e quantificação de valores da geodiversidade relevantes ao desenvolvimento do geoturismo no Caminho dos Diamantes (Estrada Real, MG)
}

\section{Methodological and theoretical basis for inventory, qualification and quantification of the relevant geodiversity values the development of geotourism in the Caminho dos Diamantes} (Estrada Real, MG, Brazil)

\author{
Suzana Fernandes de Paula, Paulo de Tarso Amorim Castro
}

\begin{abstract}
RESUMO
A difusão de informações sobre os aspectos geológicos da região em que vivemos ainda é deficiente, dificultando seu entendimento pela grande maioria das pessoas. O patrimônio geológico é composto por sítios com relevância cultural, turística, científica ou didática. Em regiões como o Caminho dos Diamantes, Minas Gerais, onde as vilas e aglomerados humanos pós-colombianos foram formados em função da atividade extrativa mineral, o patrimônio geológico também engloba os registros relevantes da mineração. Tão importantes quanto os recursos minerais extraídos são as instalações mineiras tais como as minas, galerias, escavações e construções, cujos registros estão dispersos por esta região desde o século XVIII. Neste artigo são descritos os métodos utilizados para identificação, descrição e quantificação de aspectos dos geossítios visitados. A aplicação desses métodos levou à qualificação dos geossítios e possibilitaram a comparação entre eles, estabelecendo uma ordem de relevância em termos geoturísticos.
\end{abstract}

PALAVRAS-CHAVE: Geoturismo; Caminho dos Diamantes; Inventariação de Geossítios; Qualificação de Geossítios.

\begin{abstract}
The dissemination of information about the geological features of the region in which we live is still deficient, that cause difficulties in their understanding by most people. The geological heritage is composed of sites with cultural, tourist, scientific or didactic relevance. In the Caminho dos Diamantes region ("daimond way"), Minas Gerais, where villages and post-Columbian human settlements were formed due to the mining activity, the geological heritage also encompass the relevant records of mining. As important as the extracted mineral resources are mining installations such as mines, galleries, excavations and buildings, whose records are scattered through this region since the eighteenth century. This paper describes the methods used to identify, describe and quantify aspects of the visited geosites. The application of these methods led to the qualification of geosites and enabled the comparison between them, establishing an order of relevance in geotouristic terms.
\end{abstract}

KEYWORDS: Geoturism; Caminho dos Diamantes; Geosites inventory; Geosites Qualification. 


\section{Introdução}

O conhecimento geológico, devido à superficialidade pelo qual é tratado no ensino fundamental e médio, pela complexidade de nomes, ou ainda, pela escala de tempo em que ocorrem as transformações tão amplas e por vezes lentas, ainda é um conceito pouco entendido e trabalhado para a grande maioria das pessoas, limitando a difusão das informações sobre a realidade geológica da qual fazemos parte. Porém, essas informações são fundamentais não só para entender a evolução da Terra e os processos que ocorreram até chegarmos a atual condição como também para pensarmos em ações e consequências futuras. Diante disso torna-se de suma importância a divulgação mais ampla da geologia e a necessidade de entendê-la como parte do patrimônio natural de uma região, pois o conhecimento pode ser uma medida conservacionista de sucesso de feições e afloramentos reconhecidos como importantes pela comunidade científica (BRILHA, 2005).

O Instituto Estrada Real, criado em 1999 pelo Sistema FIEMG, tem por objetivos organizar, fomentar e gerenciar o produto turístico Estrada Real que constitui a maior rota turística do país. São mais de $1.630 \mathrm{Km}$ de extensão, passando por Minas Gerais, Rio de Janeiro e São Paulo. Face a isto, o estado apresenta diversas oportunidades para o desenvolvimento de um segmento do turismo que possa basear-se no patrimônio mineiro e geológico, mas que não utilizam ou desconhecem tal abordagem. Contudo, a presente proposta visa privilegiar Lugares de Interesse Geológico e Mineiro (LIGEMs) pertencentes ao Caminho dos Diamantes (que liga Ouro Preto à Diamantina com aproximadamente $395 \mathrm{~km}$ de extensão englobando 25 cidades).

A partir da emergência em desenvolver uma metodologia que proporcione um maior conhecimento, divulgação e utilização deste patrimônio mineiro e geológico e que seja capaz de inventariar, qualificar e quantificar os Lugares de Interesse Geológico e Mineiro (LIGEMs), foi desenvolvido, no Departamento de Geologia da UFOP, o "Protocolo e Inventário de Avaliação dos Lugares de Interesse Geológico e Mineiro" (PAULA; CASTRO, 2013). A apropriação e o entendimento destas novas informações, aprendizado e conceitos pelo trade turístico é um desafio, que pode ser superado através da utilização de uma linguagem mais acessível (não simplista). Esse método de inventariação, tem como finalidade valorizar e envolver as comunidades, a partir do conhecimento minerário, geológico, geoturístico e geoconservacionista, utilizando de atitudes sustentáveis e corretivas, para a utilização deste patrimônio a fim de diminuir a distância do público em relação ao conhecimento das geociências, esclarecer e envolver as comunidades sobre à necessidade de valorização da geodiversidade local através da disponibilização de informações e atividades práticas. Além disto, o turismo geológico e mineiro poderá oferecer uma oportunidade de nova abordagem aos guias e operadores de turismo locais. Gray (2004), sugere ainda, que a geodiversidade pode ser entendida através dos seus valores intrínseco, cultural, estético, econômico, funcional e científico, valores estes, que podem ser avaliados de forma quantitativa e de distribuição espacial a partir da análise da diversidade, frequência e distribuição do conjunto destes elementos abióticos, adaptando, cálculos utilizados para definir índices de 
diversidade natural, altamente utilizados na quantificação da biodiversidade (MANOSSO; PELLITERO, 2012).

\section{Objetivos e Metas \\ Objetivo Geral}

Como objetivo geral, este trabalho pretende elaborar bases metodológicas e teóricas capazes de inventariar, qualificar e quantificar os diferentes valores explícitos na geodiversidade a fim de gerar informações relevantes ao desenvolvimento do geoturismo no Caminho do Diamante. (Estrada Real, MG).

\section{Objetivos específicos}

- Georeferenciar percursos, locais e/ou regiões passíveis ao desenvolvimento do geoturismo;

- Inventariar Regiões de Interesses Geológico e Mineiro adaptando o "Protocolo e Inventário de Avaliação dos Lugares de Interesse Geológico e Mineiro" (PAULA; CASTRO, 2013) aos Circuitos Turísticos de Minas Gerais.

- Desenvolver um banco de dados a partir da utilização do GEOSSIT, que consiste em um aplicativo de livre acesso, operado com base em informações do sistema GEOBANK (Sistema Geológico do Brasil).

- Quantificar, a partir da adaptação do cálculo de geodiversidade utilizado por Manosso e Pellitero (2012) e de analises estatísticas multivariadas, as oportunidades geoturísticas e mineiras do Caminho dos Diamantes;

- Desenvolver Mapas Temáticos que abordem questões pertinentes à geodiversidade regional, aos Lugares de Interesses Geológicos e Mineiros e possíveis pontos importantes para o desenvolvimento do geoturismo;

- Utilização dos dados levantados para a confecção de um guia geoturístico do Caminho dos Diamantes.

\section{Caracterização histórico-geográfica da área de estudo.}

Era considerada "Estrada Real" o caminho oficial autorizado pela coroa, para a circulação de pessoas e mercadorias, a abertura de outras vias era considerada crime. Conforme descrito no site do Instituto Estrada Real, estes caminhos foram "percorridos pelos escravos, pelo ouro e pela história". Assim, além de ser o principal caminho de escoamento da riqueza do país, onde a coroa procurava garantir o seu controle e fiscalização a Estrada Real passou a exercer papel fundamental no desenvolvimento cultural, político e socioeconômico do Brasil. 


\section{Roteiro turístico Estrada Real}

Criado pelo Sistema FIEMG em 1999, o Instituto Estrada Real é uma entidade que tem como finalidade organizar, fomentar e gerenciar o produto turístico Estrada Real (Figura 1). Dividido por 4 caminhos distintos e passando pelos estados de Minas Gerais, Rio de Janeiro e São Paulo, esta é considerada a maior rota turística do pais implementada a partir dos antigos caminhos "que percorriam vasta área no centro-sul do Brasil, tendo como destino principal a região das minas de ouro e diamante da capitania das Minas Gerais" (SANTOS, 2001).

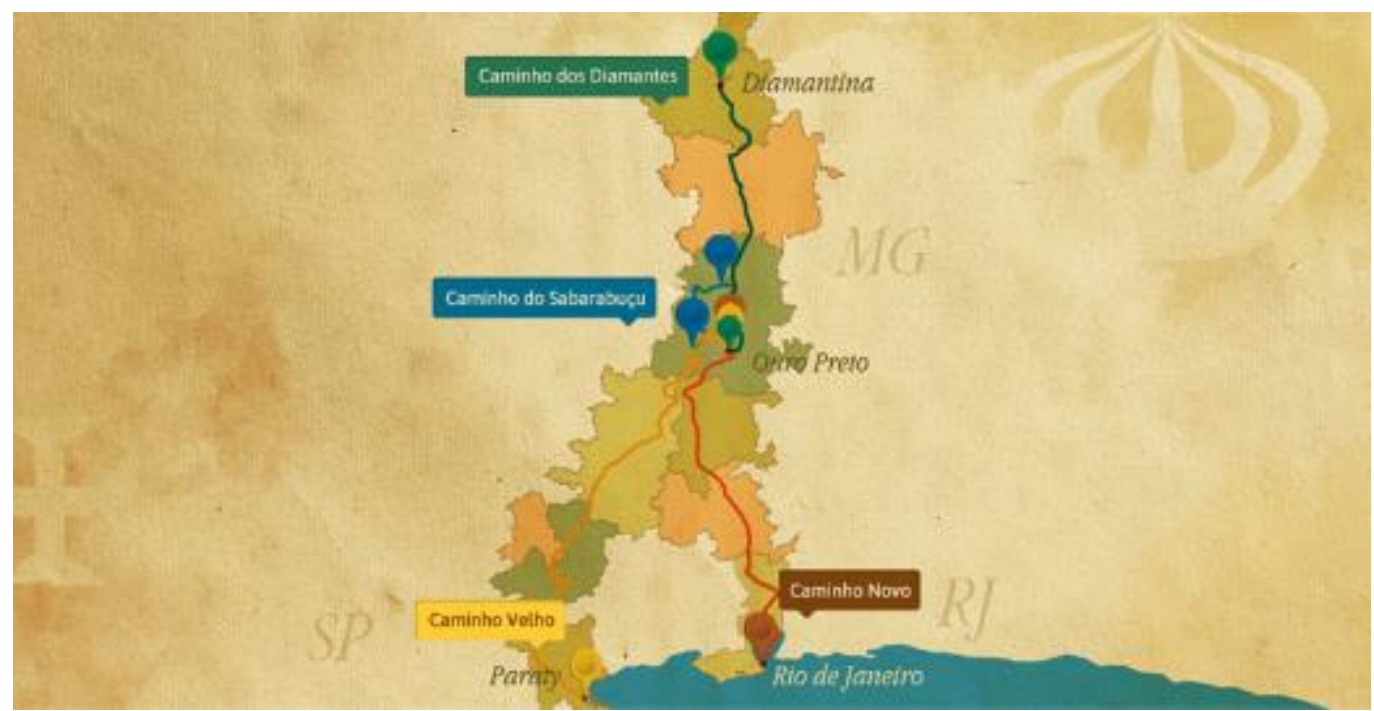

Figura 1: Mapa do Produto Turístico Estrada Real.

Fonte: Instituto Estrada Real, disponível em: http://www.institutoestradareal.com.br

Figure 1: Map of the Tourist Product Estrada Real.

Source: Instituto Estrada Real , available at: : http://www.institutoestradareal.com.br

No total, o eixo principal da Estrada Real de mais de $1600 \mathrm{~km}$ passa por 87 cidades e distritos (76 em Minas Gerais, 3 em São Paulo e 8 no Rio de Janeiro) e possui $80 \mathrm{mil} \mathrm{km}^{2}$ de área de influência.

Segundo o site do Instituto Estrada Real, o Caminho Velho foi a primeira via a ser aberta pela Coroa Portuguesa e possui $710 \mathrm{~km}$ de extensão, ligando as cidades de Paraty a Ouro Preto. Já, com $400 \mathrm{~km}$ de extensão pela Reserva da Biosfera do Espinhaço, o Caminho dos Diamantes (Ouro Preto a Diamantina), que será a área de estudo do presente trabalho, existiu em função da descoberta e exploração de diamantes. O caminho de Sabaraçu (antigo nome dado a Serra da Piedade, com 160km de extensão, teve seu início devido a crença de que o minério de ferro que brilhava ao contato com a luz solar, fosse ouro, assim criaram uma rota alternativa entre Ouro Preto (Caminho Velho) e Barão de Cocais (Caminho dos Diamantes). Por fim, o Caminho Novo passou a ser uma alternativa mais rápida e fácil ao Caminho Velho, com $515 \mathrm{~km}$, une as cidades de Ouro Preto e Rio de Janeiro. De acordo com Barbosa (2009), o processo de formação histórica dos caminhos reais foi extremamente importante para o desenvolvimento não só desta região, mas contribuiu de uma maneira geral para a formação histórica brasileira. 
Apesar de extenso, todo o caminho da Estrada Real é demarcado por totens de localização além de planilhado, descrito e com informações altimétricas, além disso, ainda é possível encontrar no site oficial, linhas do GPS e fotos para serem baixadas e relatos de viajantes que já percorreram os caminhos.

\section{Localização}

O recorte para desenvolvimento do presente trabalho será dado apenas ao Caminho dos Diamantes que, de acordo com o site do Instituto Estrada Real, possui em seu eixo principal aproximadamente $400 \mathrm{~km}$ de extensão, abrangendo 50 municípios ligando os municípios de Ouro Preto e Diamantina (Figura 2).

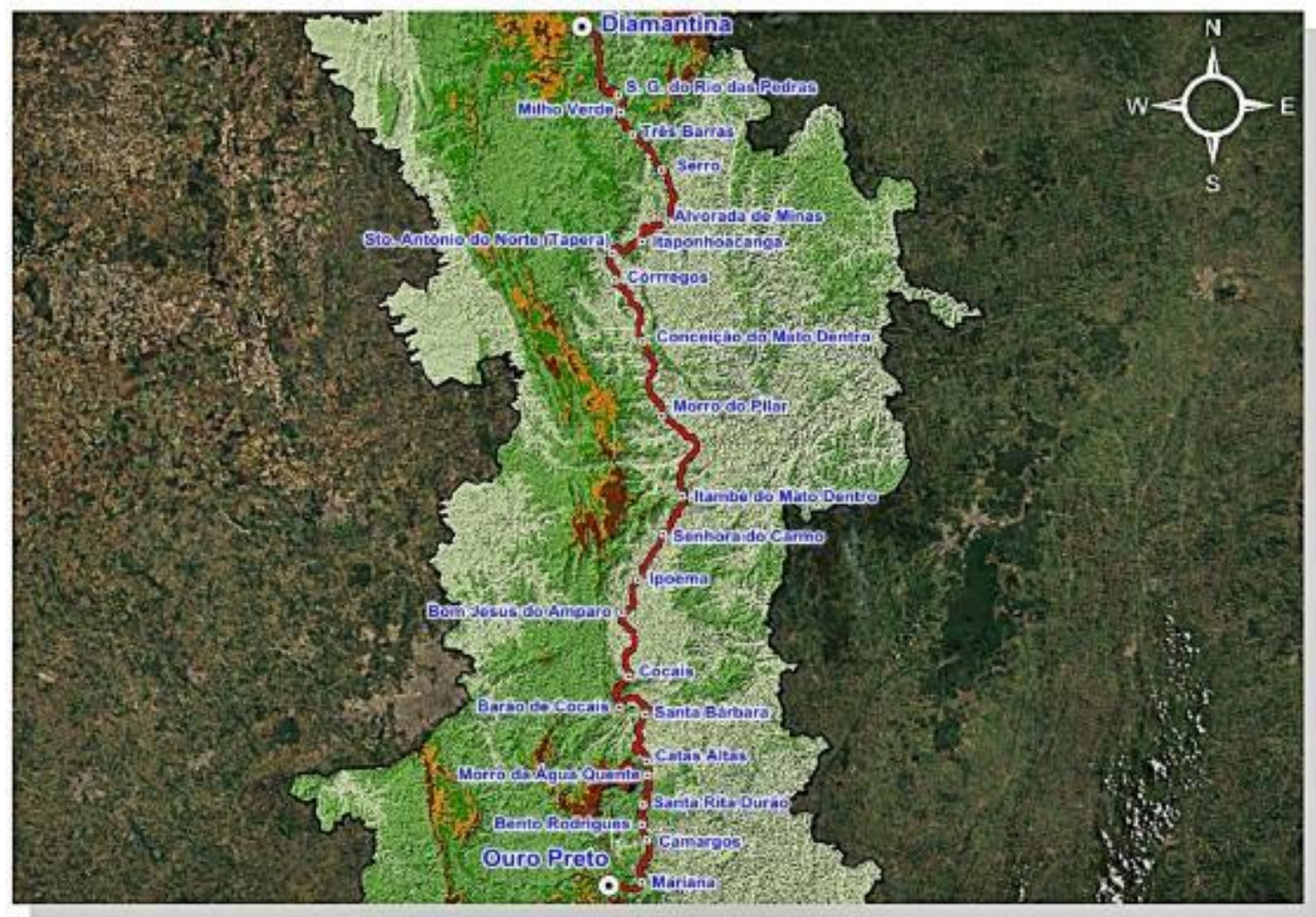

Figura 2: Mapa de localização das cidades pertencentes ao Caminho dos Diamantes. Figure 2: Location map of the cities belonging to the Diamond Way.

Fonte: Instituto Estrada Real, disponível em: http://www.institutoestradareal.com.br. Source: Instituto Estrada Real, available at http://www.institutoestradareal.com.br.

A região do Caminho dos Diamantes possui uma extensa malha viária constituída de estradas federais e estaduais que integram os municípios e, algumas, fazem parte o roteiro turístico. Destacam-se as rodovias federais (BR-381, BR-262 e BR-120) e as estradas estaduais como MG-010, MG-020, MG-262 também auxiliam no acesso às cidades mineiras que fazem parte ao Caminho dos Diamantes. 


\section{Metodologia e Estratégias de Ação}

\section{Metodologia de campo e inventariação:}

- Compilação bibliográfica;

- Compilação de base Cartográfica básica (elementos geomorfológicos e estruturais, relevo, litologia, drenagens, vegetação, acessos) para subsidiar os primeiros campos:

A partir do Portal da Geologia de Minas Gerais, um site desenvolvido a partir de uma iniciativa da Codemig em convênio com o Instituto de Geociências da UFMG e o Serviço Geológico do Brasil - CPRM, é possível o acesso e a busca de informações geológicas, disponíveis no banco de dados georreferenciados de todas as regiões de Minas Gerais.

No site do Instituto Estrada Real é possível encontrar todos os caminhos com roteiros planilhados, como demostrado no modelo de um trecho exemplificado abaixo:

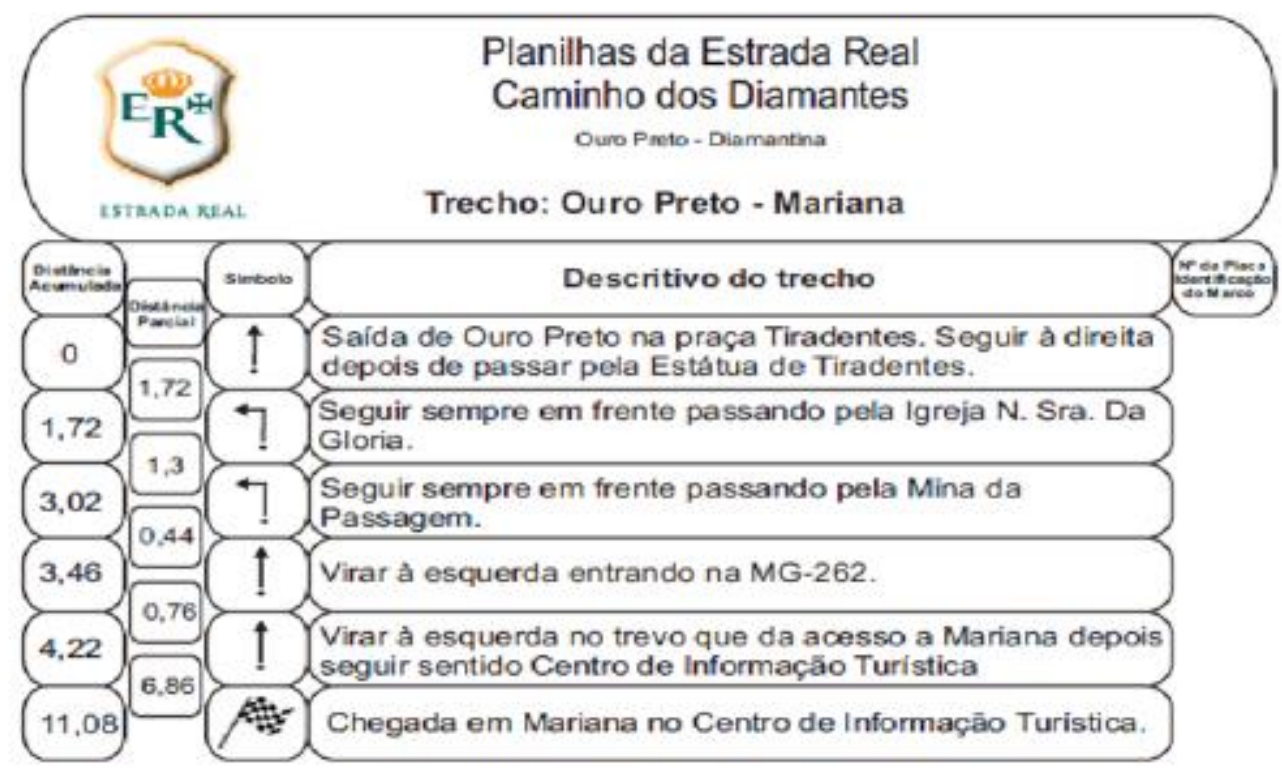

Figura 3: Trecho planilhado do Caminho dos Diamantes (Ouro Preto - Mariana). Figure 3: Excerpt from the Diamond Way (Ouro Preto - Mariana).

Fonte: Instituto Estrada Real. Disponível em: http://www.institutoestradareal.com.br/ Source: Instituto Estrada Real . Available in : http://www.institutoestradareal.com.br/

\section{- Inventariação dos Lugares de Interesse Geológico e Mineiros (LIGEMs):}

Esta inventariação será realizada através da adaptação do Protocolo de Avaliação de Lugares de Interesse Geológico e Mineiro (PAULA; CASTRO. 2013). Serão utilizados, inicialmente, os pontos com características importantes da geodiversidade, selecionados pelo Instituto Estrada Real, que fazem parte do Caminho dos Diamantes, porém, será possível que outros pontos sejam inclusos, no decorrer das visitas ao campo e a partir do contato com a comunidade local. 
A partir de uma consulta pelo site do Instituto Estrada real podemos destacar os seguintes Lugares de Interesse Geológico e Mineiro passiveis de inventariação:

- Centro Histórico de Ouro Preto;

- Vista do Pico do Itacolomi;

- Mina de Passagem de Marina;

- Centro Histórico de Mariana;

- Distrito de Camargos fundado devido a descoberta de um ribeirão aurífero;

- Distrito de Bento Rodrigues;

- Distrito de Santa Rita do Durão;

- Trajeto até o povoado de Morro d'água Quente que é feito em cima de uma montanha de minério de ferro;

- Arraial do Morro D’água Quente, que possui este nome devido fontes termais que existiam na região, mas que foram destruídas devido a escavações auríferas;

- Vista do Pico do Baiano e Serra de Catas Altas;

- Cidade de Catas Altas, fundada por bandeirantes que chegaram por conta da exploração de ouro e de pedras preciosas e que, depois do esgotamento destas minas foi substituído, conforme sugestão de Saint Hilarie, pelo ferro;

- Vista para a Serra da Caraça;

- Santuário do Caraça;

- Bicame de pedra (aqueduto construído por escravos em 1792);

- Cidade de Santa Barbara;

- Cidade de Barão dos Cocais;

- Sitio Arqueológico da Pedra Pintada;

- Vilarejo de Cocais

- Cidade de Bom Jesus do Amparo;

- Fazenda Colonial Cabo de Agosto, citada por Saint Hilaire em seus relatos de viagens;

- Museus dos Tropeiros no distrito de Ipoema;

- Cachoeira Alta no distrito de Ipoema;

- Vista da Serra do Lobo, dos Linhares e dos Alves;

- Cachoeira da Boa Vista no povoado de Senhora do Carmo;

- Cidade de Itambé do Mato Dentro;

- Duas Pedras e vista para o Travessão na Serra do Cipó (divisor das Bacias São Francisco e Doce);

- Parque Nacional da Serra do Cipó; 
- Rio do Peixe;

- Cidade de Morro do Pilar (primeira cidade da América do Sul a abrigar um alto-forno);

- Cidade de Conceição do Mato Dentro;

- Salão de Pedras;

- Lagoa Azul;

- Colina da Paz;

- Cachoeira do Tabuleiro $(19 \mathrm{~km}$ de distância de Conceição);

- Povoado de Córregos;

- Povoado de Santo Antônio do Norte (Tapera)

- Visão da Serra do Espinhaço, Serra do Intendente e Serra São Jose;

- Distrito de Itapanhoacanga;

- Duas Pontes em Itapanhoacanga;

- Povoados de Capelinha e Mato Grosso;

- Cidade de Alvorada de Minas;

- Cidade de Serro;

- Povoado de Três Barras;

- Povoado de Milho Verde;

- Povoado de São Gonçalo do Rio das Pedras;

- Visão do Pico do Itambé;

- Calcamento de pedras utilizado pelos tropeiros;

- Ponte sobre o rio Jequitinhonha;

- Caminho dos escravos de Diamantina;

- Centro Histórico de Diamantina.

\section{- Desenvolver um banco de dados a partir da utilização do aplicativo GEOSSIT.}

Este aplicativo, desenvolvido pelo Serviço Geológico Brasileiro, será utilizado como uma ferramenta de cadastro e sistematização das informações dos geossítios selecionados. A consulta é livre e o sistema operado por meio de uma base de dados específica do Geobank. Os locais selecionados já foram cadastrados e dados como identificação, enquadramento, características geológicas, interesse, conservação, entre outros, serão alimentados após os trabalhos de campo. Optou-se por também utilizar esta plataforma na catalogação dos geossítios em virtude de ser uma oportunidade de reunir as informações coletadas em uma plataforma já consolidada e que utiliza de uma tecnologia simples, eficaz e acessível. 


\section{Quantificação geoturistica:}

Utilizando de técnicas estatísticas propostas por Carcavilla ET AL (2007), onde foram adaptados fundamentos já utilizados com a finalidade de mensurar aspectos da biodiversidade, foi possível estabelecer funções que valorizam questões ligadas à geodiversidade, culminando com 0 desenvolvimento de uma metodologia própria para valorar aspectos relacionados ao geoturismo, adaptando o modelo proposto. Para isto, serão utilizadas informações que serão previamente adquiridas através da aplicação do Inventario descrito anteriormente. Nesta etapa, serão utilizadas deste material, as informações adquiridas no item 14, onde são selecionadas os interesses geoturístico de cada LIGEM. Utilizando destas informações, é possível calcular parâmetros referentes a:

- Variedade ou abundância: número de LIGEMs por área (Geodiversidade Intrínseca).

$$
\mathrm{Gi}=\mathrm{L} / \mathrm{S}
$$

Onde: $\mathrm{Gi}=$ Geodiversidade Intrínseca;

$L=$ Quantidade de LIGEMs existentes;

$$
\mathrm{S}=\text { Área }
$$

- $\quad$ Freqüência: Número de vezes que um mesmo interesse aparece na área definida.

$$
\mathrm{Fi}=\mathrm{ri} / \mathrm{S}
$$

Onde: $\mathrm{Fi}=$ Freqüência do interesse; área;

$\mathrm{Ri}$ = número de locais que o mesmo tipo de interesse aparece na

$$
\mathrm{S}=\text { Área }
$$

- Distribuição: disposição espacial dos interesses. Quanto maior esse valor, maior o grau de heterogeneidade de interesses da distribuição.

$$
\mathrm{Gf}=\mathrm{r} / \mathrm{S}
$$

Onde: $\mathrm{Gf}=$ grau de fragmentação;

$r=$ números de locais diferentes onde ocorre o mesmo tipo de interesse;

$\mathrm{S}=$ Área.

\section{- Cálculo do potencial geoturístico}

Para esta avaliação serão utilizados os critérios criados para o Inventario que possibilitam a avaliação quantitativa. A partir da soma dos valores aplicados as 14 variáveis importantes para o desenvolvimento do geoturismo, numa pontuação de 20 (condição ótima) à 0 (condição ruim), 
destes geossítios. Contudo, esses valores não pretendem avaliar a relevância de cada local, visto que, cada um, possui características igualmente importantes no que tange ao seu valor geológico e suas especificidades, a intenção em valorar e compará-los é dimensionar quais são os geossítios com maior potencialidade para desenvolver atividades que atinjam de forma mais incisiva as especificidades geoturísticas. Assim, para a quantificação destes dados utilizaremos a seguinte equação:

$$
\mathrm{Pgt}=\mathrm{Vlg} 1+\mathrm{Vlg} 2 \ldots \mathrm{Vlgn} / \mathrm{Nlg}
$$

Onde: Pgt = Potencial Geoturístico

Vlgn = Soma das variáveis de cada LIGEM (Analise quantitativa do Protocolo)

$\mathrm{Nlg}=$ Numero de LIGEM na área

\section{Confecção de Mapas temáticos}

Os dados coletados e analisados na fase de campo, serão inseridos em uma base cartográfica desenvolvida no software Arcgis $\Theta$, subsidiando assim, a confecção dos mapas temáticos.

- Compilação bibliográfica e de bases cartográficas;

- Mapas de quantificação da geodiversidade para geoturismo: Tamanho de escala e grid serão definidos a partir do número de pontos analisados e inventariados. A partir de então será possível definir qual região possui maiores oportunidades e diversidade de elementos de interesse.

- Mapas de Interesse específico: Será possível visualizar qual região de Minas Gerais é mais propicia para determinado segmento do geoturismo, de acordo com as definições do item 14 do Protocolo de Avaliação.

\section{Confecção do Guia Geoturístico do Caminho dos Diamantes (Estrada Real, MG)}

Em virtude do grande investimento e da grande visibilidade que ações como a fomentação da Estrada Real e das Associações dos Circuitos Turísticos de Minas Gerais, houve um ganho no desenvolvimento do turismo no Estado. Embora existam locais, rotas e atrativos descritos, mapeados e sinalizados, estes pontos não são entendidos, muitas vezes, pelo viés e importância de seu patrimônio geológico e mineiro. Por isso, este guia tornase uma oportunidade aos interessados em conhecerem esses locais, que além de admirar paisagens, poderão compreender o ambiente no que diz respeito à sua geodiversidade. 


\section{Considerações Finais}

Embora existam geossítios em regiões turísticas distintas, qualquer deles pode ser inventariado, utilizando deste protocolo proposto que privilegia suas características especificas. Assim será possível catalogar localidades com características geomorfológicas, sedimentológicas, estruturais, estratigráficas e/ou mineiras importantes, com relevo, enquadramentos e características geológicas que comprovam as várias possibilidades que geodiversidade oferece ao desenvolvimento do geoturismo. Desta forma, uma das primeiras providências a serem tomadas é a identificação, catalogação e inventariação destes aspectos geológicos e mineiros nos locais aptos ao desenvolvimento de atividades turísticas.

A partir de todos os dados levantados é possível qualificar, dimensionar e comparar geossítios, além de utilizar valores que quantificam suas características, resultando pontuações específicas a cada localidade. Esses valores não pretendem avaliar a relevância de cada local, visto que, cada um, possui características igualmente importantes no que tange ao seu valor geológico e suas especificidades, a intenção em valorar e compará-los é dimensionar quais são os geossítios com maior potencialidade para desenvolver atividades que atinjam de forma mais incisiva as especificidades de determinado projeto.

Além disto, o turismo geológico e mineiro poderá oferecer uma oportunidade de nova abordagem aos guias e operadores de turismo locais que estão direta e indiretamente ligados às atividades turísticas, mas que não utilizam ou desconhecem tal abordagem.

\section{Referências Bibliográficas}

BARBOSA, F.M.C.P. Vulnerabilidade Ecoturística no Caminho dos Diamantes - Estrada Real/MG. Dissertação de Mestrado apresentada ao Programa de Pós-Graduação em Geografia - Tratamento da Informação Espacial da Pontifícia Universidade Católica de Minas Gerais. Belo Horizonte, 2009.

BRILHA, J. Patrimônio Geológico e Geoconservação: a conservação da natureza na sua vertente geológica. Portugal, Palimage, 2005, 190p.

CARCAVILLA, U.L.; LÓPEZ, M.J.; DURÁN, V.J.J. Patrimonio geológico y geodiversidad:investigación, conservación, gestión y relación con los espacios naturales protegidos. Instituto Geológico y Minero de España Madrid, 2007.

CASTRO, P.T.A. O patrimõnio geológico da região de Mariana e Ouro Preto, no sul do Quadrilátero Ferrífero (MG): bases para o turismo científico e ações de sustentáveis em pequenas comunidades. Projeto de pesquisa. CNPq. UFOP, 2010.

CASTRO, P.T.A.; NALINI JR, H.A.; MOTA, H. Entendendo a Mineração no Quadrilátero Ferrífero, Belo Horizonte: Ecológico, 2012. 93p. Disponível em: <http://www.qfe2050.ufop.br/livro/Quadrilatero Ferrifero.pdf> 
CASTRO, P.T.A.; PAULA, S.F. O patrimônio geológico e mineiro dos municípios de Ouro Preto e Mariana, sul do Quadrilátero Ferrífero (MG): bases para o turismo científico e ações sustentáveis em pequenas comunidades. In: 46. Congresso Brasileiro de Geologia, 2012, Santos. Anais do 46. Congresso Brasileiro de Geologia. Rio de Janeiro: Sociedade Brasileira de Geologia, 2012. v. 1.

CPRM - Companhia de Pesquisa de Recursos Minerais. Ministério das Minas e Energia. Secretaria De Geologia, Mineração e Transformação Mineral. Serviço Geológico do Brasil.Brasília/DF- Brasil.

DORR, V.N. Mapa Lito-Estratigrafico da Região do Anticlinal de Mariana e Adjacencias. Escala: 1:25 000, 1969.

ESCHWEGE, W. L. 1833. Pluto Brasilienses. Belo Horizonte: Ed. ItatiaiaEdusp, 2v, 1979.

GEOSSIT. Companhia de Pesquisa de Recursos Minerais. Ministério das Minas e Energia. Secretaria De Geologia, Mineração e Transformação Mineral. Serviço Geológico do Brasil. Disponível em: <http://www.cprm.gov.br/geossit/>

HOSE, T.A. 3 G's for Modern Geotourism. Geoheritage Journal, v.4, pp. 724, 2012.

LICCARDO, R. Turismo Mineral em Minas Gerais, Brasil. Global Tourism.Vol.3, n², 2007.

MANOSSO, F.C; PELLITERO. R. Geodiversity: Some Considerations About Quantification and Evaluation of Spatial Distribution. Anuário do Instituto de Geociências - UFRJ. Vol 35, 2012.

NASCIMENTO, M.A.L; RUCHKYS, U.A; MANTESSO- NETO, V. Geodiversidade, Geoconservação e Geoturismo: Trinômio importante para a proteção do patrimônio geológico. SBG, 2008.

ROCHA JUNIOR, D.; VIEIRA JUNIOR, W.; CARDOSO, R.C. Viagem pela Estrada Real dos Goyazes. Brasília: Paralelo 15, 2006.

RUSCHKYS U.A. Patrimônio geológico e geoconservação no Quadrilátero Ferrífero, Minas Gerais: potencial para a criação de um Geopark da UNESCO. Instituto de Geociências, Universidade Federal de Minas Gerais, Belo Horizonte, Tese de Doutorado, 211p. 46, 2007.

SANTOS, M. Estradas reais: introdução ao estudo dos caminhos do ouro e do diamante no Brasil. Belo Horizonte: Estrada Real, 2001. 179p.

SECRETARIA DE ESTADO DE TURISMO DE MINAS GERAIS. Disponível em: $\quad<h$ ttp://www.turismo.mg.gov.br/circuitos-turisticos/informacoesadministrativas> 
Suzana Fernandes de Paula: Universidade Federal de Ouro Preto, Ouro Preto, MG, Brasil.

E-mail: thayspinho@hotmail.com

Link para o currículo Lattes: http://lattes.cnpq.br/6971545107452648

Paulo de Tarso Amorim Castro: Universidade Federal de Ouro Preto, Ouro Preto, MG, Brasil.

E-mail: thayspinho@hotmail.com

Link para o currículo Lattes: http://lattes.cnpq.br/6971545107452648

Data de submissão: 28 de abril de 2015

Data de recebimento de correções: 16 de dezembro de 2015

Data do aceite: 16 de dezembro o de 2015

Avaliado anonimamente 